\title{
Pengaruh pemberian zat retardan terhadap pertumbuhan dan hasil ubi pada dua kultivar kentang (Solanum tuberosum L.) di dataran medium
}

\author{
Effect of retardants substances on growth and seed tuber yield \\ productivty of two potato cultivars (Solanum tuberosum L.) \\ at medium land
}

Diterima : 15 September 2015/Disetujui : 15 Oktober 2015 / Dipublikasikan : Oktober 2015

CDepartment of Crop Science, Padjadjaran University

\begin{abstract}
The objective of this study was to obtain information on potato varieties and the type and concentration of retardants that can support growth, development, quantity and quality of potato seeds in medium land. The research method used was the split plot design, the main plot was the potato variety, Nadia and Granola and the subplot wasthe type and concentration of the used retardants: paklobutrazol $\left(0,40 ; 120 \mathrm{mgL}^{-1}\right)$ and coumarin(45; 90;135 $\left.\mathrm{mgL}^{-1}\right)$. The result showed that kind of variety and retardants substance affectedon growth and development of potato seed. There are have an interaction effect between variety and substance retardants for the weight of potatoes tuber per plant, butno interaction for plant height, chlorophyll content, number of tuber per plant, tuber weight per plot and the percentage of potatoes size tuber were produced. The application of retardan Nadia Varieties produced tuber weight per plant higher than the granola variety, whereas granola variety produced tuber sizes $S$ and $M$ classes higher than Nadia variety.
\end{abstract}

Keywords : Potato · Tuber · Medium land .

Retardants

Sari Tujuan dari kegiatan penelitian ini adalah untuk mendapatkan informasi mengenai kultivar kentang dan jenis serta konsentrasi zat retardan yang dapat mendukung pertumbuhan dan perkembangan serta kuantitas dan kualitas hasil ubi bibit kentang di dataran medium. Metode penelitian yang digunakan adalah

\footnotetext{
Dikomunikasikan oleh T. Nurmala

Sumadi ${ }^{1}$. E. Suminar ${ }^{1}$. Murgayanti ${ }^{1}$. A. Nuraini ${ }^{1}$

${ }^{1}$ Dept. Budadaya Pertanian Fakultas Pertanian Unpad

Korespondensi: desoendi@yahoo.com
}

Rancangan Petak terpisah. Perlakuan terdiri dari petak utama yaitu kultivar yaitu kultivar Nadia dan Granola, dan anak petak yaitu jenis dan konsentrasi zat retardan dengan penggunaan paklobutrazol ( $\left.0 ; 40 ; 120 \mathrm{mg} \mathrm{L}^{-1}\right)$ atau coumarin (45; 90; $135 \mathrm{mg} \mathrm{L}^{-1}$ ). Hasil percobaan menunjukkan bahwa jenis kultivar dan zat retardan berpengaruh terhadap pertumbuhan dan perkembangan bibit kentang. Terjadi interaksi pada peubah bobot ubi per tanaman, sedangkan peubah tinggi tanaman, kandungan klorofil, jumlah ubi per tanaman, bobot ubi per petak dan persentase jumlah ubi kentang per tanaman berdasarkan pengkelasan ubi bibit tidak terjadi interaksi antara kultivar dan zat retardan. Penggunaan zat retardan pada kultivar Nadia menghasilkan bobot ubi per tanaman lebih tinggi daripada kultivar Granola sedangkan untuk kelas ubi ukuran S dan M dihasilkan lebih tinggi pada kultivar Granola daripada kultivar Nadia.

Kata kunci : Kentang · Ubi · Dataran medium · Zat retardan

\section{Pendahuluan}

Kentang merupakan salah satu komoditas penting di dunia.Kentang adalah tanaman pangan dengan urutan ke-5 di dunia setelah padi, gandum, kedelai dan jagung, sedangkan di Benua Asia, tanaman kentang menempati urutan ke-3 setelah padi dan gandum (FAOSTAT, 2008). Secara umum produktivitas kentang di Indonesia masih relatif rendah, yaitu 16.51 ton ha $^{-1}$ dengan luas Luas pertanaman kentang pada tahun 2009 sebesar 71.238 (BPS, 2009), hal ini masih tertinggal jauh bila dibandingkan dengan pencapaian produktivitas negara Eropa Barat dan Amerika Utara yang 
mencapai $>40$ ton ha-1 ${ }^{-1}$ FAOSTAT, 2009). Setiap tahunnya konsumsi kentang mengalami peningkatan sejalan dengan pertambahan jumlah penduduk, sehingga diperlukan perluasan areal pertanaman kentang. Peningkatnya luas areal pertanaman kentang, berarti jumlah kebutuhan bibit kentang tiap tahun juga akanmeningkat.

Tanaman kentang di Indonesia secara tradisional dibudidayakan dengan menggunakan ubi sebagai bibit dan masih menjadi salah satu kendala utama dalam produksi kentang, karena harga bibit ubi yang tinggi dan ketersediaan bibit ubi berkualitas yang terbatas, hingga saat iniIndonesia masih mengimpor bibit ubi kentang. Kultivar Granola menjadi pilihan utama bagi para produsen bibit dan kentang sayur dan kultivar Nadia merupakan salah satu kultivar yang bagi masyarakat umum masih belum banyak dikenal namun memiliki potensi yang cukup tinggi.

Usaha memenuhi kebutuhan bibit kentang dapat dilakukan dengan memperluas pertanam-an di dataran medium untuk tujuan produksi bibit kentang unggul bermutu, namun kendala yang dihadapi temperatur relatif tinggi dan perbedaan suhu malam-siang yang sempit dapat mengakibatkan produksi ubi kentang menjadi sangat rendah. Suhu yang tinggi merupakan faktor pembatas keberhasilan pertumbuhan tanaman kentang pada dataran medium yang dapat menurunkan partisi asimilat ke ubi, sebaliknya partisi asimilat ke bagian lain meningkat (Wolf et al., 1990; Vandam et al., 1996), hal ini disebabkan produksi dan aktivitas giberelin meningkat sehingga menghambat proses pembentukkan ubi. Zat retardan yang berperan dalam menghambat aktivitas giberelin serta dapat menginisiasi pengubian diantaranya adalah paklobutrazol (Tekalign and Hammes, 2005) dan coumarin (Stallknecht and Farnsworth, 1982).

\section{Bahan dan Metode}

Percobaan dilakukan di lahan milik petani sayuran di desa Cibungur kecamatan Rancakalong dengan ketinggian tempat sekitar 700 meter di atas permukaan laut (dpl), pada tanah dengan jenis tanah Inceptisol dan curah hujan $C_{3}$ menurut klasifikasi Oldeman. Waktu percobaan di lapangan telah berlangsung mulai bulan Maret - Oktober 2012.

Bahan-bahan yang digunakan dalam percobaan ini adalah ubi bibit kultivar Nadia dan Granola kelas $G_{2}$ (benih pokok) berasal dari PD Hikmah Pangalengan Kabupaten Bandung, selaku produsen bibit kentang bersertifikat. Bahan lain Dolomit, Zat retardan paklobutrazol dan coumarin, pupuk kandang, Urea, SP-18 dan pupuk $\mathrm{KCl}$. Untuk mengendalikan hama dan penyakit menggunakan fungisida Antilla dengan bahan aktif Mankozeb $80 \%$ konsentrasi $2 \mathrm{~g} \mathrm{~L}^{-1}$ dan insektisida Marcis dengan bahan aktif Deltametrin $25 \mathrm{~L}^{-1}$ konsentrasi $2 \mathrm{cc} \mathrm{L}^{-1}$, dan Karbofuran $3 \%$ untuk menghindari serangga dan hama tanah

Rancangan percobaan yang digunakan adalah Rancangan Petak terpisah dengan 14 kombinasi perlakuan yang diulang sebanyak 3 kali,sehingga terdapat 42 satuan percobaan. Dalam satu percobaan perlakuan terdapat 8 tanaman. Perlakuan terdiri dari petak utama yaitu kultivar yaitu kultivar Nadia dan Granola, dan anak petak yaitu jenis dan konsentrasi zat retardan dengan penggunaan paklobutrazol ( $\left.0 ; 40 ; 120 \mathrm{mg} \mathrm{L}^{-1}\right)$ atau coumarin $\left(45 ; 90 ; 135 \mathrm{mg} \mathrm{L}^{-1}\right)$.

\section{Hasil dan Pembahasan}

Tinggi tanaman. Hasil analisis ragam menunjukkan bahwa tidak terjadi interaksi antara kultivar kentang dengan zat retardan. Rata-rata tinggi tanaman kedua kultivar (Nadia dan Granola) tidak menunjukkan pengaruh yang berbeda terhadap peubah tinggi tanaman pada 3 dan 5 mst sedangkan pemberian zat retardan pada 3 mst belum menunjukkan pengaruh yang berbeda tetapi pada $5 \mathrm{mst}$ terjadi pengaruh yang berbeda diantara perlakuan zat retardan (Tabel 1).

Tabel 1 menunjukkan bahwa penggunaan zat retardan jenis paklobutrazol tidak selalu menghasilkan rata-rata tinggi tanaman yang lebih rendah daripada kontrol. Aloni dan Paskkar (1987 dalam Lolaei et al. 2013) menyatakan bahwa paklobutrazol dapat menghambat biosintesis GA3, selain itu Davis dan Curry (1991) juga melaporkan bahwa paklobutrazol dapat menurunkan pertumbuhan ke atas terutama menurunkan panjang ruas bergantung pada jenis species dan kultivar kentang. Hal ini menunjukkan bahwa penurunan sintesis giberelin yang diakibatkan karena pemberian paklobutrazol menyebabkan penurunan pada sel proliferasi yang menyebabkan penurunan pada pemanjangan batang dan perluasan daun. 
Tabel 1. Rata-rata Tinggi Tanaman pada 3 dan 5 mst.

\begin{tabular}{|c|c|c|}
\hline \multirow[t]{2}{*}{ Perlakuan } & \multicolumn{2}{|c|}{ "Tinggi Tanaman (cm) } \\
\hline & $3 \mathrm{mst}$ & $5 \mathrm{mst}$ \\
\hline \multicolumn{3}{|c|}{ Kultivar (V) } \\
\hline $\mathrm{V}_{1}$ & $18,63 \mathrm{a}$ & 33,44 a \\
\hline $\mathrm{v}_{2}$ & $18,11 \mathrm{a}$ & $31,92 \mathrm{a}$ \\
\hline \multicolumn{3}{|c|}{ Jenis dan Konsentrasi Zat Retardan (Z) } \\
\hline $\mathrm{z}_{0}$ & $17,17 \mathrm{a}$ & $32,94 \mathrm{ab}$ \\
\hline $\mathrm{z}_{1}$ & 17,30 a & $31,11 \mathrm{ab}$ \\
\hline $\mathrm{z}_{2}$ & 17,56 a & $34,67 \mathrm{bc}$ \\
\hline $\mathrm{z}_{3}$ & $19,61 \mathrm{a}$ & $37,06 \mathrm{c}$ \\
\hline $\mathrm{Z}_{4}$ & $18,74 \mathrm{a}$ & $31,39 \mathrm{ab}$ \\
\hline $\mathrm{Z}_{5}$ & 19,56 a & $31,44 \mathrm{ab}$ \\
\hline $\mathrm{Z}_{6}$ & 18,65 a & 30,17 a \\
\hline
\end{tabular}

$\overline{\text { Keterangan : Angka rata-rata pada tiap kolom yang }}$ diikuti huruf yang sama menunjukkan tidak berbeda nyata menurut Uji Jarak Berganda Duncan taraf $5 \%$

Pertumbuhan tinggi tanaman dapat dipengaruhi oleh jenis dan konsentrasi zat retardan. Pemberian zat retardan jenis coumarin menghasilkan rata-rata tinggi tanaman yang lebih rendah daripada pemberian paklobutrazol namun tidak berbeda nyata dengan kontrol namun pemberian paklobutrazol pada $120 \mathrm{mg} \mathrm{L}^{-1}$ menghasilkan nilai rata-rata tinggi tanaman yang tertinggi tetapi tidak berbeda dengan konsentrasi $80 \mathrm{mg} \mathrm{L}^{-1}$. Faktor lain yang diduga mempengaruhi tinggi tanaman adalah lingkungan dengan suhu di dataran medium yang relatif tinggi sehingga menyebabkan terjadinya peningkatan pertumbuhan pada daun dan batang akibat aktivitas giberelin terus meningkat.

Hamdani (2008) menyatakan bahwa pada suhu tanah $22{ }^{\circ} \mathrm{C}$ bobot kering bagian atas tanaman meningkat karena suhu tanah yang tinggi dapat mengakibatkan peningkatan tinggi tanaman kentang akibat perpanjangan ruas batang maupun peningkatan panjang batang. Perpanjangan ruas batang ini disebabkan oleh kandungan gibberelat dalam tanaman yang tinggi dipacu oleh suhu tinggi sedangkan pengaruh giberelin dapat memacu pertumbuhan bagian atas tanaman melalui peningkatan pembelahan dan perpanjangan sel.

Kandungan Klorofil. Pengukuran kandungan klorofil sangat penting untuk menentukan nilai kemampuan fotosintesis (Xie et al. 2011). Hasil analisis ragam menunjukkan tidak terdapat pengaruh yang berbeda antara kultivar dengan zat retardan terhadap kandungan klorofil. Pemberian zat retardan jenis paklobutrazol maupun coumarin tidak memberikan pengaruh yang nyata dibandingkan dengan kontrol namun peningkatan konsentrasi zat retardan baik paklobutrazol maupun coumarin menyebabkan kandungan klorofilnya menurun (Tabel 3.). Hal ini sejalan dengan hasil penelitian Wieland dan Wample (1985 dalam Jungklang dan Saenil, 2012) yang menyatakan bahwa paklobutrazol juga tidak berpengaruh nyata terhadap kandungan klorofil tanaman apel.

Tabel 3. Nilai Rata-rata Kandungan Klorofil.

\begin{tabular}{cc}
\hline \hline Perlakuan & Kandungan Klorofil \\
\hline Kultivar (V) & $54,39 \mathrm{a}$ \\
$\mathrm{V}_{1}$ & $52,80 \mathrm{a}$ \\
$\mathrm{V}_{2}$ & $54,10 \mathrm{a}$ \\
\hline \multicolumn{2}{c}{ Jenis dan Konsentrasi Zat Retardan (Z) } \\
$\mathrm{Z}_{0}$ & $55,77 \mathrm{a}$ \\
$\mathrm{Z}_{1}$ & $53,53 \mathrm{a}$ \\
$\mathrm{Z}_{2}$ & $53,98 \mathrm{a}$ \\
$\mathrm{Z}_{3}$ & $55,17 \mathrm{a}$ \\
$\mathrm{Z}_{4}$ & $51,37 \mathrm{a}$ \\
$\mathrm{Z}_{5}$ & $51,22 \mathrm{a}$ \\
$\mathrm{Z}_{6}$ & \\
\hline \hline
\end{tabular}

$\overline{\text { Keterangan : Angka rata-rata pada tiap kolom yang }}$ diikuti huruf yang sama menunjukkan tidak berbeda nyata menurut Uji Jarak Berganda Duncan taraf 5\%

Jumlah Ubi per Tanaman (knol) dan Bobot Ubi per Petak (knol). Hasil analisis ragam menunjukkan tidak terjadi interaksi antara jenis kultivar dengan zat retardan yang diberikan terhadap peubah jumlah ubi per tanaman dan bobot ubi per petak. Jumlah ubi per tanaman baik untuk kedua jenis kultivar maupun pemberian zat retardan menunjukkan hasil yang tidak berbeda sedangkan pada peubah bobot ubi per petak faktor kultivar tidak menunjukkan pengaruh yang berbeda namun pemberian zat retardan memberikan pengaruh yang berbeda.Penggunaan zat retardan jenis paklobutrazol maupun comarin menghasilkan bobot ubi per petak yang lebih tinggi daripada kontrol meskipun pada konsentrasi coumarin yang lebih tinggi bobot ubi yang dihasilkan tidak berbeda dengan kontrol (Tabel 4.).

Peranan zat retardan jenis palobutrazol dalam pembentukan ubi seperti yang dilaporkan oleh Tekaligns dan Hammes (2005), bahwa paklobutrazol dapat menghambat biosintesis giberelin dan asam absisi (ABA) sehingga dapat meningkatkan kandungan klorofil, kinerja fotosintesis, memicu proses pengumbian lebih awal tanpa mengurangi jumlah ubi dan pada akhirnya mempengaruhi hasil dan jumlah ubi. 
Tabel 4. Nilai Rata-rata Jumlah Ubi per Tanaman dan Bobot Ubi per Petak

\begin{tabular}{ccc}
\hline \hline Perlakuan & $\begin{array}{c}\text { Jumlah ubi per } \\
\text { tanaman (Knol) }\end{array}$ & $\begin{array}{c}\text { Bobot ubi per } \\
\text { petak (g) }\end{array}$ \\
\hline Kultivar (V) & \multicolumn{3}{c}{} \\
$\mathrm{V}_{1}$ & $20,05 \mathrm{a}$ & $680.11 \mathrm{a}$ \\
$\mathrm{V}_{2}$ & $22,71 \mathrm{a}$ & $763.92 \mathrm{a}$ \\
\hline \multicolumn{3}{l}{ Jenis dan Konsentrasi Zat Retardan (Z) } \\
$\mathrm{Z}_{0}$ & $14,33 \mathrm{a}$ & $510,28 \mathrm{a}$ \\
$\mathrm{Z}_{1}$ & $21,00 \mathrm{a}$ & $759,72 \mathrm{~b}$ \\
$\mathrm{Z}_{2}$ & $18,83 \mathrm{a}$ & $806,17 \mathrm{~b}$ \\
$\mathrm{Z}_{3}$ & $27,00 \mathrm{a}$ & $805,85 \mathrm{~b}$ \\
$\mathrm{Z}_{4}$ & $19,17 \mathrm{a}$ & $763,77 \mathrm{~b}$ \\
$\mathrm{Z}_{5}$ & $23,00 \mathrm{a}$ & $822,93 \mathrm{~b}$ \\
$\mathrm{Z}_{6}$ & $26,33 \mathrm{a}$ & $585,40 \mathrm{ab}$ \\
\hline \hline
\end{tabular}

Keterangan : Angka rata-rata pada tiap kolom yang diikuti huruf yang sama menunjukkan tidak berbeda nyata menurut Uji Jarak Berganda Duncan taraf $5 \%$

Coumarin dapat mempengaruhi proses pembentukan ubi kentang (El-Sawy et al. 2007), pada percobaan ini pemberian Coumarin pada konsentrasi antara 45-90 mg L-1 diduga cukup efektif dalam menghambat pertumbuhan cabang pada tanaman kentang.Pemberian zat retardan jenis paklobutrazol maupun coumarin, secara umum menghasilkan bobot ubi per petak yang lebih tinggi dibandingkan dengan kontrol walaupun pada pemberian coumarin dengan konsentrasi $135 \mathrm{mg} \mathrm{L}^{-1}$ menghasilkan bobot ubi per petak yang tidak berbeda nyata dengan kontrol dan lebih rendah daripada perlakuan lainnya.

Berdasarkan Tabel 5. terlihat bahwa terjadi interaksi antara jenis kultivar dengan zat retardan terhadap bobot ubi per tanaman. Kultivar Nadia $\left(\mathrm{v}_{1}\right)$, pemberian berbagai jenis dan konsentrasi retardan memberikan pengaruh yang berbeda. Bobot ubi tertinggi diperoleh dengan pemberian pada $\mathrm{z}_{1}$ (40 $\mathrm{mg} \mathrm{L}^{-1}$ paklobutrazol) dan $\mathrm{Z}_{3}$ (120 $\mathrm{mg} \mathrm{L}^{-1}$ paklobutrazol) namun tidak berbeda nyata dengan $\mathrm{z}_{4}\left(45 \mathrm{mg} \mathrm{L}^{-1}\right.$ coumarin) dan $\mathrm{Z}_{5} \quad\left(135 \mathrm{mg} \mathrm{L}^{-1}\right.$ coumarin), sedangkan pada kultivar Granola terlihat bahwa pemberian $\mathrm{Z}_{5}$ (135 $\mathrm{mg} \mathrm{L}^{-1}$ coumarin) menghasilkan bobot ubi per tanaman yang relatif lebih tinggi walaupun tidak berbeda dengan kontrol.

Tabel 5. Bobot Ubi per Tanaman (g).

\begin{tabular}{cccccccc}
\hline \hline \multirow{2}{*}{$(\mathrm{V})$} & \multicolumn{7}{c}{$\mathrm{Z}$} \\
\cline { 2 - 8 } & $\mathrm{z}_{0}$ & $\mathrm{z}_{1}$ & $\mathrm{z}_{2}$ & $\mathrm{z}_{3}$ & $\mathrm{z}_{4}$ & $\mathrm{z}_{5}$ & $\mathrm{z}_{6}$ \\
\hline \multirow{2}{*}{$\mathrm{v}_{1}$} & $49,05 \mathrm{~b}$ & $50,87 \mathrm{~b}$ & $44,58 \mathrm{a}$ & $54,14 \mathrm{~b}$ & $56,13 \mathrm{~b}$ & $49,97 \mathrm{~b}$ & $41,31 \mathrm{a}$ \\
& $\mathrm{BC}$ & $\mathrm{CD}$ & $\mathrm{AB}$ & $\mathrm{CD}$ & $\mathrm{D}$ & $\mathrm{BCD}$ & $\mathrm{A}$ \\
& $40,6 \mathrm{a}$ & $34,67 \mathrm{a}$ & $43,09 \mathrm{a}$ & $42,12 \mathrm{a}$ & $42,7 \mathrm{a}$ & $43,77 \mathrm{a}$ & $48,4 \mathrm{~b}$ \\
$\mathrm{~V}_{2}$ & $\mathrm{AB}$ & $\mathrm{A}$ & $\mathrm{B}$ & $\mathrm{AB}$ & $\mathrm{B}$ & $\mathrm{BCD}$ & $\mathrm{B}$ \\
\hline \hline
\end{tabular}

Keterangan : Angka rata-rata pada tiap kolom yang diikuti huruf yang sama menunjukkan tidak berbeda nyata menurut Uji Jarak Berganda Duncan taraf 5\%

Tabel 6.Nilai Rata-rata Persentase Jumlah Ubi Kentang Pertanaman Kelas SS, S, M, L1, L2 dan LL yang Dihasilkan.

\begin{tabular}{|c|c|c|c|c|c|c|}
\hline \multirow[b]{2}{*}{ Perlakuan } & \multicolumn{6}{|c|}{ \%\% Ukuran Ubi } \\
\hline & SS & $S$ & $\mathbf{M}$ & L1 & L2 & LL \\
\hline \multicolumn{7}{|l|}{$(\mathrm{V})$} \\
\hline $\mathrm{v}_{1}$ & $4,65 b$ & $28,93 a$ & $32,46 a$ & $26,86 a$ & $4,11 \mathrm{a}$ & $2,97 a$ \\
\hline $\mathrm{v}_{2}$ & $4,62 \mathrm{a}$ & $30,19 b$ & $34,97 a$ & $24,14 \mathrm{a}$ & $3,88 \mathrm{a}$ & $2,50 \mathrm{a}$ \\
\hline \multicolumn{7}{|l|}{$\overline{(Z)}$} \\
\hline $\mathrm{z}_{0}$ & $4,58 \mathrm{a}$ & $27,56 \mathrm{ab}$ & $37,87 \mathrm{C}$ & $23,77 \mathrm{ab}$ & $3,82 \mathrm{a}$ & $2,71 \mathrm{a}$ \\
\hline $\mathrm{Z}_{1}$ & $4,86 a$ & $32,60 b$ & $32,10 \mathrm{ab}$ & $23,33 a$ & $3,85 a$ & $2,7 a$ \\
\hline $\mathrm{z}_{2}$ & $4,54 \mathrm{a}$ & $31,59 \mathrm{ab}$ & $33,12 \mathrm{abc}$ & $28,06 \mathrm{ab}$ & $3,57 a$ & $2,68 \mathrm{a}$ \\
\hline $\mathrm{Z}_{3}$ & $4,1 \mathrm{a}$ & $28,46 a b$ & $34,23 b c$ & $24,62 \mathrm{ab}$ & $3,59 a$ & $3,49 a$ \\
\hline $\mathrm{Z}_{4}$ & $4,81 \mathrm{a}$ & $28,71 \mathrm{ab}$ & $34,50 \mathrm{bc}$ & $24,69 \mathrm{ab}$ & $3,45 a$ & $2,56 a$ \\
\hline $\mathrm{Z}_{5}$ & $4,74 a$ & $30,64 \mathrm{ab}$ & $35,66 \mathrm{bc}$ & $24,33 a b$ & $3,68 \mathrm{a}$ & $2,33 a$ \\
\hline $\mathrm{Z}_{6}$ & $4,88 \mathrm{a}$ & $27,37 a$ & $28,50 a$ & $29,71 b$ & $4,26 \mathrm{a}$ & $2,66 \mathrm{a}$ \\
\hline
\end{tabular}

Keterangan : Angka rata-rata pada tiap kolom yang diikuti huruf yang sama menunjukkan tida berbeda menurut Uji Jarak berganda Duncan taraf $5 \%$. 
Coumarin dapat memicu pengumbian lebih awal pada kedua kultivar dan bobot ubi pertanaman yang relatif lebih tinggi diduga laju asimilasi tinggi sehingga berdampak langsung pada meningkatnya jumlah dan bobot ubi. Senyawa triazole dapat menghambat biosintesis giberelin tetapi menstimulasi biosintesis sitokinin dan asam absisat yang dapat meng-induksi pembentukan ubi (Jaleel et al. 2008 dalam Rajalekshmi et al. 2009) demikian juga peran coumarin dapat mempercepat proses pembentukan ubi dengan mengurangi kandungan giberelin (Mashhadi dan Moeini 2015).

Persentase Jumlah Ubi Kelas LL, L2, L, M, S dan SS. Hasil analisis statisik jumlah ubi per tanaman kelas LL, L2, L, M, S dan SS menunjukkan bahwa interaksi antara kultivar dengan jenis dan konsentrasi zat retardan memberikan pengaruh yang tidak berbeda terhadap jumlah ubi pertanaman untuk kelas SS, S, M, L1, L2, dan LL. Perlakuan kultivar memberikan pengaruh yang berbeda pada ubi ukuran SS dan S sedangkan pada ukuran lainnya pengaruhnya tidak berbeda, namun perlakuan zat retardan memberikan pengaruh yang berbeda pada ukuran ubi S, M, dan L1. Ukuran ubi SS yang dihasilkan pada Kultivar Nadia lebih tinggi daripada kultivar granola, sedangkan persentase ubi ukuran $S$ kultivar granola lebih banyak daripada nadia (Tabel 6.), sedangkan pemberian zat retardan menunjukkan ukuran ubi S, M, L1 berada pada kisaran 27.37-35.66 \%, namun secara umum hasil percobaan menunjukkan bahwa pemberian zat retardan memberikan hasil yang tidak berbeda dengan kontrol.

Perlakuan $\mathrm{z}_{6}$ pada persentase ukuran ubi $\mathrm{S}$ dan $\mathrm{M}$ menghasilkan nilai yang lebih rendah daripada perlakuan lainnya, hal ini menunjukkan bahwa pemberian zat retardan jenis coumarin pada konsentrasi yang tinggi tidak lebih baik daripada perlakuan lainnya. Diduga peranan suhu yang tinggi di dataran medium mempengaruhi pembentukan ubi.Muthoni dan Kabira (2015) menyatakan bahwa suhu tinggi dapat menurunkan hasil ubi kentang dengan meningkatnya laju perkembangan dan respirasi yang lebih tinggi.

\section{Kesimpulan dan Saran}

Kesimpulan. Terjadi interaksi antara jenis kultivar kentang dengan jenis dan konsentrasi zat retardan terhadap peubah bobot ubi per tanaman, sedangkan pada peubah tinggi tanaman, kandungan klorofil, jumlah ubi per tanaman, bobot ubi per petak dan persentase jumlah ubi kentang per tanaman berdasarkan pengkelasan ubi bibit tidak terjadi interaksi.

Saran. Untuk pertanaman kentang di Desa Cibungur Kecamatan Rancakalong Kabupaten Sumedang dapat direkomendasikan dengan penanaman kentang kultivar Nadia dengan penggunaan zat retardan paklobutrazol $40 \mathrm{mg} \mathrm{L-}$ 1 atau $45 \mathrm{mg} \mathrm{L}^{-1}$ coumarin, sedangkan untuk kultivar Granola tidak diperlukan tambahan zat retardan dalam menghasilkan bobot ubi per tanaman tertinggi.

\section{Ucapan Terima Kasih}

Terima kasih disampaikan kepada Lembaga Penelitian dan Pengabdian kepada Masyarakat Universitas Padjadjaran yang telah mendanai kegiatan ini melalui Program Penelitian Hibah Kompetitif Universitas Padjadjaran Tahun 2012.

\section{Daftar Pustaka}

BPS. 2009. Survei Pertanian. Produksi Tanaman Sayuran di Indonesia. http//www.bps.go. id. 4 Februari 2011.

Davis, T.D. and E.A. Curry. 1991. Chemical regulation of vegetative growth. Critical Rev. Plant Sci., 10: 151-188.

El-Sawy, A., S. Bekheet, U. Ibrahimaly. 2007. Morphological and molecular and characterization of potato microtubers production on coumarin inducing medium. Int.J. Agric \& Biol. 9(5):675-680.

Food and Agriculture Organization of The United Nations. 2008. Top production world (total). Diakses : http://faostat.fao. org/site/339/default.aspx (22/03/2011).

Food And Agriculture Organization of The United Nations. 2009. Top production world (total). Diakses :http://faostat.fao. org/site/339/default.aspx (22/03/2011).

Gardner FP. , Pearce \& Mitchell L. 1991. Fisiologi Tanaman Budidaya (Terjemahan Herawati Susilo). UI Press. hal.268-269.

Hamdani, J.S. 2008. Perngaruh jenis mulsa terjadap pertumbuhan dan hasil tiga kultivar kentang (Solanum tuberosum L.) yang ditanam di dataran medium. J. Agron. Indonesia 37 (1):14-20. 
Jungklang, J., and K. Saengnil. 2012. Effect of paklobutrazol on patumma cv. Chiang Mai Pink under water stress. Songklanakarin J. Sci. Techno. 34 (4): 361-366.

Lolaei A., S. Mobasheri, R. Bemana, N. Teymori. 2013. Role of paclobutrazol on vegetative and sexual growth of plants. Int' $1 \mathrm{~J}$. of Agric. and Crop Sci. Vol. 5 (9): 958-961.

Mashhadi S., Moeini MJ. 2015. The effect of cytokinin and coumarin on in vitro microtuberization of potato (Solanum tuberosum L.) Cv. Marfona. Ludus Vitalis. Vol. XI (1): 165-170.

Muthoni J., J.N. Kabira. 2015. Potato production in the hot tropical areas of Africa: Progress made in breeding for heat tolerance. J. of Agricultural Science Vol. 7 (9) : 2015

Rajalekshmi, KM., Jaleel CA., Azooz MM, Pannereselvam R. 2009. Effect of triazole growth regulator on growth and pigment content in Plectanthus aromaticus and Plectranthus vettiveroids. Adv. Biol. Research. 3(3-4): 117-122.
Tekalign, $\mathrm{T}$ and Hammes, P.S. 2005. Growth responses of potato (Solanum tuberosum) grown in a hot tropical lowland to applied paklobutrazol. J. Crop \& Hort. Sci. 33:35-102.

Vandam, J., Kooman, P.L, Struik, P.C. 1996: Effect of temperature and photoperiod on early growth and final number of tubers in potato (Solanum tuberosum L.) Pot. Res. 39:51-62.

Wolf, S., A. Marani, J. Rudich. 1990: Effects of temperature and photoperiode on assimilate partitioning in potato plant. Annals of Botany 66:515-520.

Xie, XJ., SHH Shen, X.Y. Zhao, and F.D. Xu. 2011. Effect of photosynthetic characteristic and dry matter accumulation of rice under high temperature at heading stage. African J. Agric. Res. Vol. 6(7): 1931-1940.

Stallknecht, G.F. and S. Farnsworth. 1982. General characteristics of coumarin induced tuberization of axillary shoots of Solanum tuberosum L cultured in vitro. Am. Potato J. 59, 17-32. 